\title{
C-reactive protein level and microbial aetiology in patients hospitalised with acute exacerbation of COPD
}

\author{
Tristan W. Clark ${ }^{1,2}$, Marie-Jo Medina2, Sally Batham², Martin D. Curran³, \\ Surendra Parmar ${ }^{3}$ and Karl G. Nicholson ${ }^{2}$
}

Affiliations: ${ }^{1}$ Dept of Clinical and Experimental Sciences and Respiratory Biomedical Research Unit, University of Southampton, Southampton, UK. ${ }^{2}$ Dept of Infection, Immunity and Inflammation, University of Leicester, Leicester, UK. ${ }^{3}$ Public Health England, Clinical Microbiology and Public Health Laboratory, Addenbrooke's Hospital, Cambridge, UK.

Correspondence: Tristan W. Clark, Dept of Clinical and Experimental Sciences and Respiratory Biomedical Research Unit, University of Southampton, LF101, South Academic block, Southampton General Hospital, Southampton, S016 6YD, UK. E-mail: T.W.Clarkdsoton.ac.uk

ABSTRACT Both viruses and bacteria are thought to cause exacerbations of chronic obstructive pulmonary disease (COPD); however, the relative importance of each remains uncertain. C-reactive protein (CRP) levels increase during exacerbations but the relationship with aetiology is not established. We aimed to explore the relationship between serum CRP and the rate of detection of viruses and bacteria.

This was a prospectively recruited, observational study of patients hospitalised with exacerbations of COPD. Nasopharyngeal swabs were tested for respiratory viruses by reverse transcriptase-PCR. Sputum and blood were collected for bacterial culture and urine tested for pneumococcal antigen. CRP levels were measured on sera. CRP and other factors associated with viral, bacterial or mixed detection were assessed using multiple logistic regression analysis.

264 patients with exacerbations of COPD were studied: $26 \%$ tested positive for respiratory viruses only, $13 \%$ had bacteria only, $12 \%$ had mixed viral/bacterial detection, and $49 \%$ had no pathogens detected. CRP level and temperature were strongly associated with viral detection rate $(\mathrm{p}<0.001$ and $\mathrm{p}=0.004$, respectively) and mixed viral/bacterial detection rate $(\mathrm{p}=0.02$ and $\mathrm{p}=0.03$, respectively) on multivariate analysis. Bacterial detection rate was not associated with CRP level or body temperature.

This study supports the role of viruses as important aetiological agents causing exacerbations of COPD.

@ERSpublications

Detection of respiratory viruses strongly associated with CRP level and temperature in hospitalised COPD patients http://ow.ly/Ac24U

This article has supplementary material available from erj.ersjournals.com

Received: May 202014 | Accepted after revision: Aug 022014 | First published online: Sept 032014

Clinical trial: This study is listed on the International Standard Randomized Controlled Trial Number Register (identifier ISRCTN21521552).

Support statement: This work was supported by the National Institute of Health Research though the Health Technology Assessment programme (grant number 03/39/18). The views and opinions expressed in this manuscript are those of the authors and do not necessarily reflect those of the Health Technology Assessment programme, the National Institute of Health Research, the NHS or the Department of Health.

Conflict of interest: Disclosures can be found alongside the online version of this article at erj.ersjournals.com

Copyright OERS 2015 


\section{Introduction}

An estimated 3 million people in the UK have chronic obstructive pulmonary disease (COPD) and the incidence is increasing worldwide [1]. Exacerbations of COPD are associated with increased medication use, prolonged hospital stays and significant mortality rates [2]. Most exacerbations are thought to be caused by respiratory infection, with both viruses and bacteria being implicated, although the relative importance of each is not well established. Historically, bacteria have been considered the most important pathogens causing exacerbations but their exact role remains uncertain as they are detected in only 30 $50 \%$ of COPD exacerbations [3], and can be found in a similar proportion of patients and at equivalent concentrations in those who are clinically stable [3, 4]. Studies demonstrating the development of strain-specific antibodies to bacteria following exacerbation suggest that acquisition of a different strain of the same bacterial species may play a role [5-7], although new strain acquisition is not invariably associated with exacerbation [8]. Studies using modern sensitive molecular methods have demonstrated that viruses are commonly detected in patients with exacerbations of COPD [9-12]. In addition, the changes in inflammatory profile, less frequent detection in steady state and the seasonal changes in exacerbation rate suggest that viral acquisition is causally related to exacerbation [9-12]. Furthermore, recent challenge studies with human rhinovirus in patients with COPD have replicated the symptoms and inflammatory profile changes associated with naturally occurring exacerbations [13]. Studies examining bacterial and viral co-infection in COPD exacerbations have suggested a synergistic relationship between the two [12, 14], with a recent study demonstrating a quantitative change in bacteria in the lower respiratory tract of COPD patients following experimental rhinovirus challenge [15]. A longitudinal study of naturally occurring human rhinovirus-induced COPD exacerbations has demonstrated that secondary bacterial infection developed in $73 \%$ of patients by 14 days post onset of symptoms, suggesting that bacterial infection may become important later in the course of a viral-induced exacerbation [16].

C-reactive protein (CRP) is an acute phase protein that increases with infectious and inflammatory conditions and is measured routinely in clinical care. CRP levels increase during exacerbations of COPD but are not well correlated to severity or outcome [17, 18]. Few studies have examined the relationship between microbial aetiology and CRP levels in patients with exacerbations of COPD.

As exacerbations are thought to be caused by infectious agents and are accompanied by an inflammatory response, we hypothesised that the detection rate of viruses and bacteria would be associated with CRP levels if these agents are causally related to the exacerbation. Therefore, we aimed to compare CRP levels and other factors in patients with viruses only detected, bacteria only detected, mixed viral/bacteria detection and those with no pathogen detected using descriptive statistics, and to explore these relationships using multivariate analysis. Finally we aimed to examine individual viral and bacterial subtypes to evaluate their contribution to any relationship between pathogen detection rate and CRP levels.

\section{Methods}

\section{Subjects}

Patients were adults hospitalised with acute exacerbation of COPD as identified by discharge International Classification of Disease, 10th edition code classification [19] and confirmed by case note review. All patients had a diagnosis of COPD documented in hospital case notes and general practitioner records and $98 \%$ of patients were taking COPD medications (inhaled corticosteroids, bronchodilators and mucolytic agents) at the time of hospitalisation. Subjects were participants in a larger, prospective study of rapid, near patient testing for Streptococcus pneumoniae and influenza and met the following inclusion criteria; aged $>18$ years; able and willing to give written informed consent (or a relative or carer is able and willing to give informed assent); acute exacerbation of a chronic cardiorespiratory disease or new onset of acute cardiorespiratory illness of $<7$ days duration; and able to be recruited within $16 \mathrm{~h}$ of hospital admission. Exclusion criteria included: did not meet inclusion criteria; alternative diagnosis; participation in another study within 30 days; and diagnosis on admission of myocardial infarction or angina. Patients were recruited between the months of September and May from 2005 to 2008, across two hospital sites with acute medical admission units, within the University Hospitals of Leicester NHS Trust (Leicester, UK). Patients transferred directly from the emergency department to the critical care unit were not included although patients who were admitted to medical wards and subsequently deteriorated and required critical care admission were included. The study was approved by the Leicestershire, Northamptonshire and Rutland Ethics Committee (all UK) and all patients gave informed written consent.

\section{Clinical data}

Demographic and clinical data were collected at enrolment and outcome data was collected retrospectively from case notes and recorded on a standardised case report form. All patients had a chest radiograph 
performed within $24 \mathrm{~h}$ of admission and all radiographs were reported by a consultant radiologist. Patients with consolidation on chest radiographs (i.e. pneumonia) were excluded.

\section{Samples}

Blood, urine, sputum and nasopharyngeal swab samples were collected at enrolment by trained research staff. Blood cultures were incubated aerobically and anaerobically using the automated BacT/ALERT 3D blood culture system (bioMerieux, Durham, NC, USA). Sputum was examined by Gram stain microscopy according to local protocols and reported semi-quantitatively. Sputum was cultured on sheep blood agar and chocolate agar according to local protocols. Urine was tested for S. pneumoniae antigens using the NOW S. pneumoniae urinary antigen tests (Binax, Portland, ME, USA). Nasopharyngeal swabs were stored in viral transport medium and frozen at $-70^{\circ} \mathrm{C}$ prior to testing. Respiratory virus detection was defined as the detection of any respiratory virus nucleic acid on nasopharyngeal swab samples by real-time reverse transcriptase (RT)-PCR. Bacterial detection was defined by a positive urinary antigen test for S. pneumoniae, or positive cultures of blood or sputum with an organism deemed to be significant.

\section{Real-time multiplex RT-PCR for respiratory viruses}

Four quadruplex real-time (TaqMan; Applied Biosystems (Life Technologies S.A.), Madrid, Spain) RT-PCR assays including an internal control (bacteriophage MS2) were used to detect respiratory virus nucleic acid on nasopharyngeal swab samples, including: influenza A and B; respiratory syncytial virus (RSV) A and B; parainfluenza types 1-4; adenovirus; enterovirus; rhinovirus; human metapneumovirus (hMPV); group 1 coronaviruses (HCoV-229E and HCoV-NL63); and group 2 coronaviruses (HCoV-OC43 and $\mathrm{HCoV}-\mathrm{HKU} 1)$. Full primer and probe sequences and details of the molecular methods are given in Appendix A [20-23].

\section{Statistical analysis}

Data were analysed using PRISM Version 6 (Graphpad Software, La Jolla, CA, USA) and Stata version 12 (Stata Corporation, College Station, TX, USA). Categorical data are presented as frequencies and percentage, and continuous data as median (interquartile range). Medians were compared using the Mann-Whitney U-test and proportions compared using the Chi-squared test and Fisher's exact test as appropriate. Continuous data were categorised for logistic regression analysis, which was undertaken separately for virus only detection, bacteria only detection and mixed viral/bacterial detection, using a two-step approach. The main exposures of interest were CRP and temperature on admission. Age was considered a forced variable a priori. Antibiotic use prior to hospitalisation, which could influence the detection of pathogens, was considered an important confounder and therefore included in all multivariable models. In the first step of the analysis, odds ratios adjusted for age were calculated for each variable in turn with corresponding $95 \%$ confidence intervals and $\mathrm{p}$-values from the likelihood ratio test. Variables associated with pathogen detection with a $\mathrm{p}$-value $<0.1$ were shortlisted for the multivariable analysis. In the multivariable analysis shortlisted variables were added to a model with CRP on admission, temperature on admission, antibiotic use prior to hospitalisation and age. Adjusted odds ratios were calculated, with 95\% confidence intervals and p-values derived from the likelihood ratio test.

\section{Results}

264 patients were studied. Figure 1 shows the flowchart for patients included in the study. In total, 100 (38\%) out of 264 patients tested positive for respiratory viruses, 69 (26\%) as virus only detected and 31 $(12 \%)$ as mixed viral/bacterial detection. The detected viruses were: picornaviruses (rhinoviruses $\mathrm{n}=43$ and enteroviruses $n=3)$, influenza $A$ and $B(n=18)$, coronaviruses $(n=13)$, parainfluenza viruses $(n=11)$, RSV $(n=9)$, hMPV $(n=9)$ and adenovirus $(n=1)$. In total, $66(25 \%)$ patients had bacteria detected: $35(13 \%)$ as a bacteria only detection and $31(12 \%)$ as a mixed viral/bacterial detection. The detected bacteria were: Haemophilus influenza $(\mathrm{n}=34), S$. pneumoniae (urine antigen positive $\mathrm{n}=16$, sputum culture positive $\mathrm{n}=7$ and positive in both $\mathrm{n}=2)$, Pseudomonas aeruginosa $(\mathrm{n}=9)$, Moraxella catarrhalis $(\mathrm{n}=5)$, and Staphylococcus aureus $(\mathrm{n}=3)$.

Table 1 shows the demographic, clinical and outcome data for patients with viruses only detected, bacteria only detected, mixed viral/bacterial detection and no pathogen detected. Comparison across patient groups showed no difference in age, sex, smoking status, influenza vaccination status, comorbidity, duration of illness prior to hospitalisation, antibiotic use prior to hospitalisation, antibiotic or oral corticosteroid use during hospitalisation, duration of hospital stay or mortality. Median CRP levels and body temperature were significantly different across the groups $(p<0.001$ and $p<0.001$, respectively). CRP was higher in the virus only detection group compared to the no pathogens detected group $(p<0.001)$ and the virus only detection group compared to the bacteria only detection group $(\mathrm{p}=0.08)$, although this did not reach statistical significance. There was no difference in CRP level between the bacteria only detection group and 
FIGURE 1 Flowchart for patients included in the study. Results of the subgroup analysis for only those patients with sputum samples available for culture $(n=137)$ are detailed in Appendix B. COPD: chronic obstructive pulmonary disease; CRP: C-reactive protein.

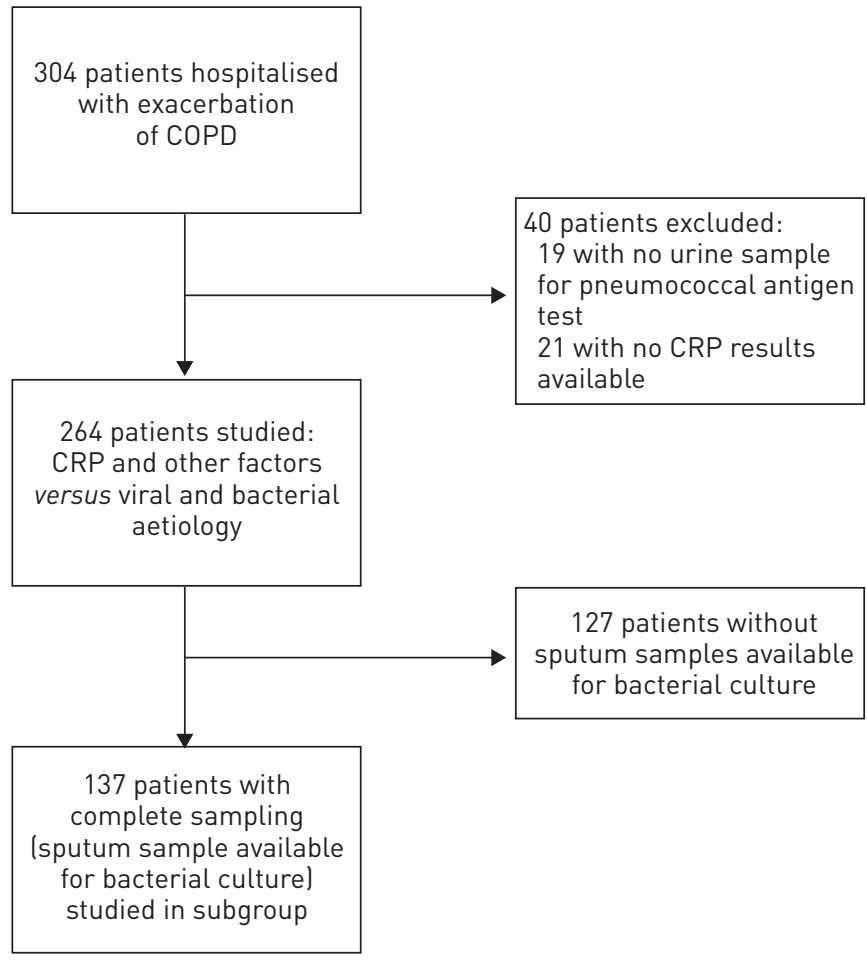

the no pathogens detected group $(\mathrm{p}=0.18)$ or between the mixed viral/bacterial detection and the virus only detection group $(\mathrm{p}=0.31)$. Temperature was higher in the virus only detection group compared to the no pathogens detected group $(\mathrm{p}<0.001)$ and the virus only detection group compared to the bacteria only detection group $(p=0.003)$. There was no difference in temperature between the bacteria only detection group and the no pathogens detected group $(\mathrm{p}=0.62)$, or between the mixed viral/bacterial detection group and the virus only detection group $(\mathrm{p}=0.75)$. Figure 2 shows the comparison of CRP levels and temperature between the four groups.

Antibiotic use was more common in patients with viruses only $(88 \%)$ and mixed virus/bacterial detection (88\%) compared to patients with bacteria only $(78 \%)$ and no pathogens detected (75\%), although this did not reach statistical significance $(\mathrm{p}=0.08)$. Subgroup analysis of only those patients with sputum samples available for bacterial culture $(n=137)$ showed similar results to the main cohort with regards to temperature and CRP (table S1).

Table 2 shows the adjusted odds ratios for the detection of viruses only by univariate and multivariate analysis. On multivariate analysis, CRP levels were strongly associated with viral detection rate $(\mathrm{p}<0.001)$. Body temperature was also strongly associated with viral detection rate $(p=0.004$, test for linear trend $\mathrm{p}<0.001)$. On univariate analysis there was an association between virus detection rate and duration of illness prior to hospitalisation $(\mathrm{p}=0.03)$; however, this association disappeared on multivariate analysis $(\mathrm{p}=0.16)$.

Table 3 shows the adjusted odds ratio for the detection of bacteria only by univariate and multivariate analysis. On multivariate analysis, CRP level and temperature were not associated with bacterial detection rate $(p=0.47$ and $p=0.71$, respectively). On multivariate analysis, antibiotic use prior to hospitalisation was not associated with a difference in bacterial detection rate $(\mathrm{p}=0.37)$.

Table 4 shows the adjusted odds ratio for the detection of mixed viral/bacterial infection by univariate and multivariate analysis. On multivariate analysis, CRP levels and body temperature were associated with mixed viral/bacterial detection rate $(\mathrm{p}=0.02$ and $\mathrm{p}=0.03$, respectively). On multivariate analysis antibiotic use prior to hospitalisation was not associated with a difference in mixed viral/bacterial detection rate $(\mathrm{p}=0.46)$. There was an association between age and mixed viral/bacteria detection with detection less likely in those aged $>80$ years $(\mathrm{p}=0.07)$, although this did not reach statistical significance. Figure 3 shows the detection rates of viruses only, bacteria only, mixed viral/bacterial detection and no pathogens detected by CRP level and temperature.

Examining viral and bacterial subtypes for patients with virus only detection and bacteria only detection demonstrated a significant association between the detection rates of influenza, rhino-enterovirus and "other" viruses (coronavirus, parainfluenza, RSV, hMPV and adenovirus), CRP levels and temperature. 
TABLE 1 Demographic, clinical and outcome data for all patients and those with viruses only, bacteria only, mixed virus and bacterial, and no pathogens detected

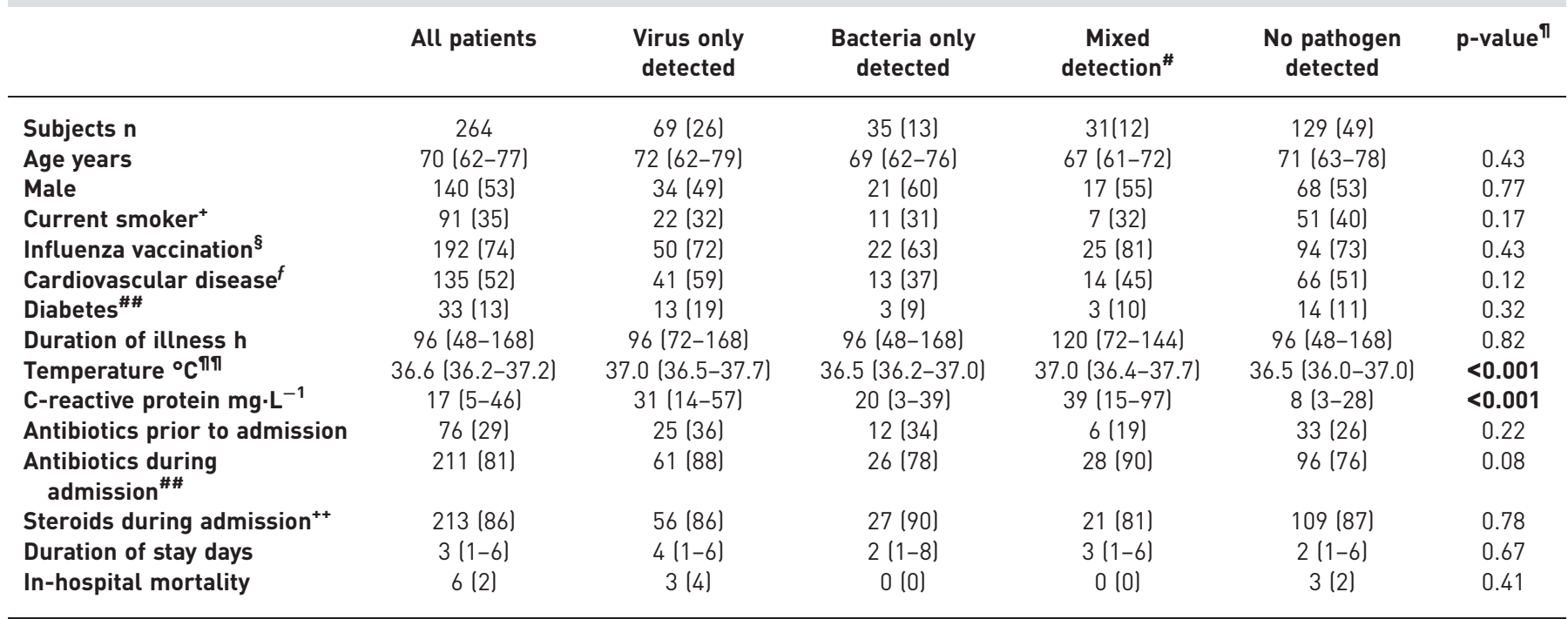

Data are presented as median (interquartile range) or $\mathrm{n}(\%)$, unless otherwise stated. Bold indicates statistical significance. ${ }^{\#}$ : concurrent detection of viruses and bacteria; ${ }^{\text {ๆ }}$ : Chi-squared across all groups; ${ }^{+}: n=263 ;{ }^{\S}: n=258 ;{ }^{f}: n=259 ;{ }^{\# \#}: n=260 ;{ }^{\text {ๆा }}: n=257 ;{ }^{++}: n=247$.

Detection of all virus types was less likely with CRP levels $<10 \mathrm{mg} \cdot \mathrm{L}^{-1}(\mathrm{p}<0.001)$ and a temperature $<37^{\circ} \mathrm{C}$ $(\mathrm{p}<0.001)$. Rhino-enterovirus was most commonly detected in patients with CRP levels of $10-50 \mathrm{mg} \cdot \mathrm{L}^{-1}$ (OR 4.0, 95\% CI 1.8-9.0; $\mathrm{p}<0.001$ ) whereas influenza was most commonly detected in patients with CRP levels of $50-100 \mathrm{mg} \cdot \mathrm{L}^{-1}$ (OR 7.6, 95\% CI 2.7-21.3; $\mathrm{p}=0.004$ ). There was no association between the detection rate of bacterial subtypes and CRP level or temperature. Figure 4 shows viral and bacterial subtype detection rate by CRP and temperature.

\section{Discussion}

This is the largest study examining CRP and aetiology in hospitalised patients with exacerbations of COPD and, to our knowledge, the only study to examine the association between CRP and viral and bacterial subtypes. It demonstrates that the detection rate of respiratory viruses was strongly associated with CRP

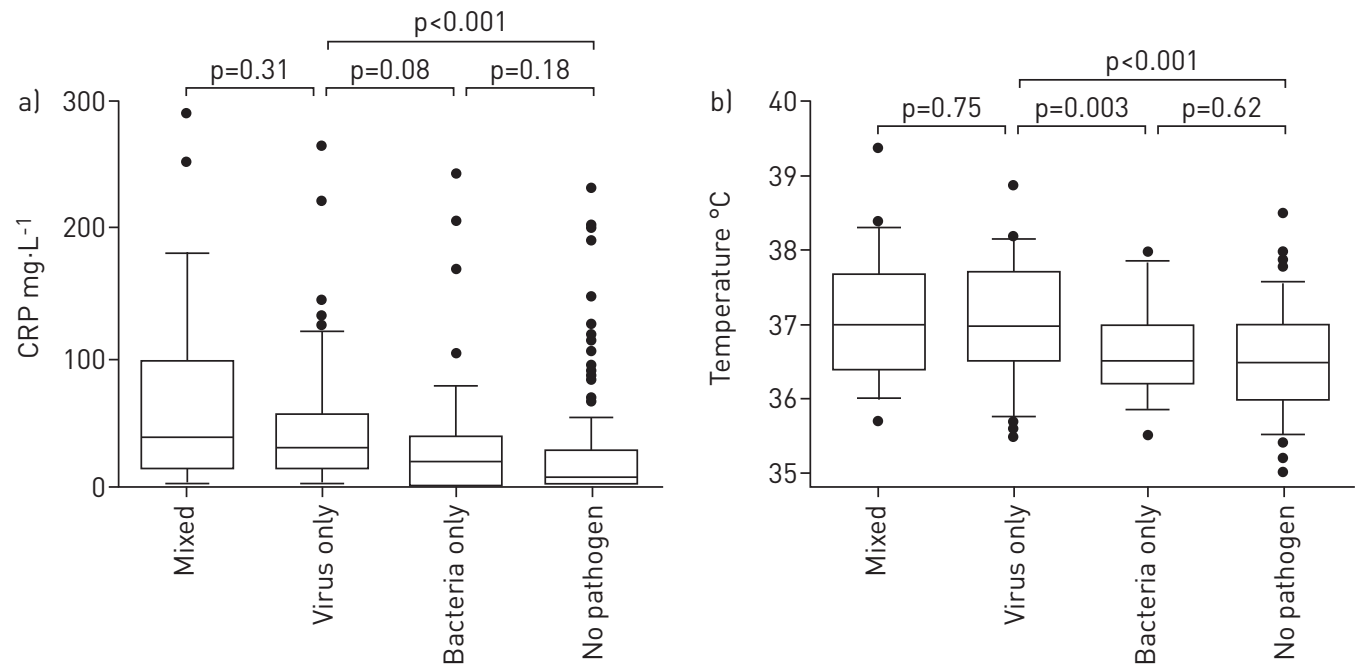

FIGURE 2 Box and whisker plots showing a) serum C-reactive protein (CRP) levels and b) body temperature in patients with mixed viral and bacterial detection, virus only detected, bacteria only detected, and no pathogen detected. Data are presented as median (interquartile range). 
TABLE 2 Factors associated with virus only detection compared to no pathogens detected by univariate and multivariate analysis

\begin{tabular}{|c|c|c|c|c|c|}
\hline Variable & $\begin{array}{l}\text { Virus only detected/ virus } \\
\text { only detected + no pathogen } \\
\text { detected }\end{array}$ & Baseline model ${ }^{\#}$ & p-value & Multivariate model & $\mathrm{p}$-value \\
\hline Total & $69 / 198$ & & & & \\
\hline$<10$ & $13 / 85(15)$ & 1 & $<0.001$ & 1 & $<0.001$ \\
\hline $10-50$ & $36 / 71(51)$ & $5.6(2.7-12.0)$ & & $4.6(2.0-10.4)$ & \\
\hline \multicolumn{6}{|c|}{ Temperature ${ }^{\circ} \mathrm{C}^{+}$} \\
\hline Total & $66 / 192$ & & & & \\
\hline$<37.0$ & $31 / 123(25)$ & 1 & $<0.001$ & 1 & 0.004 \\
\hline $37.0-37.5$ & $16 / 43(37)$ & $1.7(0.8-3.7)$ & & $1.2(0.5-2.7)$ & \\
\hline$>37.5$ & $19 / 26(73)$ & $8.0(3.1-20.9)$ & & $5.3(1.8-15.6)$ & \\
\hline \multicolumn{6}{|l|}{ Age years } \\
\hline Total & $69 / 198$ & & & & \\
\hline Male & $35 / 96(35)$ & 1 & 0.65 & NA & \\
\hline Female & $34 / 102(34)$ & $1.1(0.6-2.1)$ & & NA & \\
\hline \multicolumn{6}{|c|}{ Antibiotics prior to admission } \\
\hline Total & $69 / 198$ & & & & \\
\hline No & $44 / 140(31)$ & 1 & 0.14 & 1 & 0.11 \\
\hline Yes & $25 / 58(43)$ & $1.6(0.9-3.0)$ & & $1.8(0.8-3.8)$ & \\
\hline \multicolumn{6}{|c|}{ Duration of illness days } \\
\hline Total & $69 / 198$ & & & & \\
\hline$>5$ & $22 / 69$ (32) & 1 & 0.03 & 1 & 0.16 \\
\hline $3-5$ & $34 / 74(46)$ & $1.8(0.9-3.6)$ & & $1.7(0.8-3.9)$ & \\
\hline$\leqslant 2$ & $13 / 55(24)$ & $0.7(0.3-1.5)$ & & $0.8(0.3-2.0)$ & \\
\hline \multicolumn{6}{|c|}{ Diabetes mellitus } \\
\hline \multicolumn{6}{|c|}{ Current smoker } \\
\hline Total & $69 / 197$ & & & & \\
\hline No & 47/124 (38) & 1 & 0.23 & NA & \\
\hline Yes & $22 / 73(30)$ & $0.7(0.4-1.3)$ & & NA & \\
\hline \multicolumn{6}{|c|}{ Influenza vaccination } \\
\hline Total & $67 / 193$ & & & & \\
\hline Yes & $50 / 145(35)$ & 1 & 0.97 & NA & \\
\hline No & $17 / 48(35)$ & $1.0(0.5-2.0)$ & & NA & \\
\hline
\end{tabular}

Data are presented as $\mathrm{n} / \mathrm{N}(\%)$ or adjusted OR $(95 \% \mathrm{Cl})$, unless otherwise stated. Bold indicates statistical significance. NA: not included. \#: adjusted for age; १: adjusted for C-reactive protein and temperature on admission, age, antibiotic use prior to admission and duration of illness prior to admission; ${ }^{+}$: also associated with viral detection rate as a linear trend $(p<0.001)$.

level and body temperature on admission to hospital, whereas the detection rate of bacteria was not. Increasingly frequent detection of viruses with increasing levels of CRP and temperature in our multivariate model supports other evidence for the causal nature of the association between detected viruses and exacerbation of COPD. In addition, the association between increasing CRP and viral detection rate was maintained across all virus types including influenza, rhinovirus and other viruses. The levels of CRP associated with specific virus types in our study are consistent with a previous study examining the natural kinetics of CRP levels over time in patients with acute respiratory illness [24]. As 
TABLE 3 Factors associated with bacteria only detection compared to no pathogens detected by univariate and multivariate analysis

Variable

Bacteria only detected/bacteria Baseline model ${ }^{\#}$ p-value

Multivariate model" $\quad$-value only detected + no pathogen detected

\begin{tabular}{|c|c|c|c|c|c|}
\hline \multicolumn{6}{|c|}{ C-reactive protein $\mathrm{mg} \cdot \mathrm{L}^{-1}$} \\
\hline Total & $35 / 164$ & & \multirow{5}{*}{0.39} & & \multirow{5}{*}{0.47} \\
\hline$<10$ & 15/87 (17) & 1 & & 1 & \\
\hline $10-50$ & $13 / 48(27)$ & $1.8(0.8-4.2)$ & & $1.6(0.7-3.9)$ & \\
\hline $51-100$ & $2 / 13(15)$ & $0.9(0.2-4.4)$ & & $0.8(0.2-4.0)$ & \\
\hline$>100$ & $5 / 16(31)$ & $2.4(0.7-8.3)$ & & $2.4(0.7-8.9)$ & \\
\hline \multicolumn{6}{|c|}{ Temperature ${ }^{\circ} \mathrm{C}$} \\
\hline Total & $34 / 160$ & & \multirow{4}{*}{0.7} & & \\
\hline$<37.0$ & $25 / 117(21)$ & 1 & & 1 & \multirow[t]{3}{*}{0.71} \\
\hline $37.0-37.5$ & $6 / 33(18)$ & $0.8(0.3-2.1)$ & & $0.7(0.3-2.0)$ & \\
\hline$>37.5$ & $3 / 10(30)$ & $1.6(0.4-6.7)$ & & $1.4(0.3-6.4)$ & \\
\hline \multicolumn{6}{|l|}{ Age years } \\
\hline Total & $35 / 164$ & & \multirow{4}{*}{0.64} & & \multirow{4}{*}{0.69} \\
\hline$\leq 65$ & 14/55 (25) & 1 & & 1 & \\
\hline $66-80$ & $16 / 85(19)$ & $0.7(0.3-1.5)$ & & $0.7(0.3-1.7)$ & \\
\hline$>80$ & $5 / 24(21)$ & $0.8(0.2-2.5)$ & & $0.7(0.2-2.3)$ & \\
\hline \multicolumn{6}{|l|}{ Sex } \\
\hline Total & $35 / 164$ & & \multirow{3}{*}{0.48} & & \\
\hline Male & $21 / 89(24)$ & 1 & & NA & \\
\hline Female & 14/75 (19) & $0.8(0.4-1.6)$ & & NA & \\
\hline \multicolumn{6}{|c|}{ Antibiotics prior to admission } \\
\hline Total & $35 / 164$ & & & & \multirow{3}{*}{0.37} \\
\hline No & 23/119 (19) & 1 & \multirow[t]{2}{*}{0.37} & 1 & \\
\hline Yes & $12 / 45(27)$ & $1.5(0.6-3.4)$ & & $1.5(0.6-3.6)$ & \\
\hline \multicolumn{6}{|c|}{ Duration of illness days } \\
\hline Total & $35 / 164$ & & \multirow{4}{*}{0.67} & & \\
\hline$>5$ & 12/59 (20) & 1 & & NA & \\
\hline $3-5$ & $14 / 54(25)$ & $1.3(0.6-3.2)$ & & NA & \\
\hline$\leqslant 2$ & 9/51 (18) & $0.9(0.3-3.3)$ & & NA & \\
\hline \multicolumn{6}{|c|}{ Diabetes mellitus } \\
\hline Total & $35 / 163$ & & \multirow{3}{*}{0.72} & & \\
\hline No & $32 / 146(22)$ & 1 & & NA & \\
\hline Yes & 3/17 (18) & $0.8(0.2-2.9)$ & & NA & \\
\hline \multicolumn{6}{|c|}{ Cardiovascular disease } \\
\hline Total & $35 / 163$ & & \multirow{3}{*}{0.17} & & \\
\hline No & 22/83 (27) & 1 & & NA & \\
\hline Yes & $13 / 80(16)$ & $0.6(0.3-1.3)$ & & NA & \\
\hline \multicolumn{6}{|c|}{ Current smoker } \\
\hline Total & $35 / 164$ & & \multirow{3}{*}{0.32} & & \\
\hline No & $24 / 101(24)$ & 1 & & NA & \\
\hline Yes & $11 / 62(18)$ & $0.7(0.3-1.5)$ & & NA & \\
\hline \multicolumn{6}{|c|}{ Influenza vaccination } \\
\hline Total & $34 / 160$ & & \multirow{3}{*}{0.24} & & \\
\hline Yes & 22/117 (19) & 1 & & NA & \\
\hline No & $12 / 43(28)$ & $1.6(0.7-3.7)$ & & NA & \\
\hline
\end{tabular}

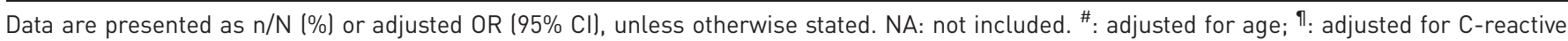
protein and temperature on admission, age, and antibiotic use prior to admission.

with asthma exacerbations, it seems likely that respiratory viruses are the principal initiating infectious agent in exacerbations of COPD, with new bacterial infections being of lesser importance. The reasons as to the relatively low rate of viral detection in exacerbations of COPD compared to asthma are unclear, although the overall detection rate of $38 \%$ in this study is highly consistent with other studies [9-11].

In contrast, the lack of association between bacterial detection rate and CRP levels or body temperature suggests that bacterial detection during exacerbation may often represent airway colonisation [25]. In our study, patients with mixed detection of viruses and bacteria behaved similarly to the patients with viruses only detected suggesting that the viral component was responsible for the associations between mixed 
TABLE 4 Factors associated with mixed viral and bacterial detection compared to no pathogens detected by univariate and multivariate analysis

\begin{tabular}{|c|c|c|c|c|c|}
\hline Variable & $\begin{array}{l}\text { Mixed viral and bacterial detection/mixed } \\
\text { viral and bacterial detection + no pathogen } \\
\text { detected }\end{array}$ & Baseline model ${ }^{\#}$ & p-value & Multivariate model" & p-value \\
\hline Total & $31 / 160$ & & & & \\
\hline$<10$ & $6 / 78$ (8) & 1 & \multirow{2}{*}{$<0.001$} & 1 & \multirow[t]{2}{*}{0.02} \\
\hline $10-50$ & $11 / 46(24)$ & $3.8(1.3-11.3)$ & & $3.0(1.0-9.2)$ & \\
\hline \multicolumn{6}{|c|}{ Temperature ${ }^{\circ} \mathrm{C}^{+}$} \\
\hline Total & $31 / 157$ & & \multirow{4}{*}{0.002} & & \\
\hline$<37.0$ & $15 / 107(14)$ & 1 & & 1 & \multirow[t]{3}{*}{0.03} \\
\hline $37.0-37.5$ & $8 / 35(23)$ & $1.7(0.6-4.4)$ & & $1.2(0.4-3.6)$ & \\
\hline$>37.5$ & $8 / 15$ (53) & $8.5(2.6-30.0)$ & & $4.8(1.3-18.0)$ & \\
\hline \multicolumn{6}{|l|}{ Age years } \\
\hline \multicolumn{6}{|l|}{ Sex } \\
\hline Total & $31 / 160$ & & \multirow{3}{*}{0.87} & & \\
\hline Male & $17 / 85(20)$ & 1 & & NA & \\
\hline Female & $14 / 75$ (19) & $0.9(0.6-2.1)$ & & NA & \\
\hline \multicolumn{6}{|c|}{ Antibiotics prior to admission } \\
\hline Total & $31 / 160$ & & \multirow{3}{*}{0.27} & & \multirow{3}{*}{0.46} \\
\hline No & $25 / 121(21)$ & 1 & & 1 & \\
\hline Yes & $6 / 39(15)$ & $0.6(0.2-1.6)$ & & $0.7(0.2-2.0)$ & \\
\hline \multicolumn{6}{|c|}{ Duration of illness days } \\
\hline Total & $31 / 160$ & & \multirow{4}{*}{0.07} & & \multirow{4}{*}{0.1} \\
\hline$>5$ & $8 / 55(15)$ & 1 & & 1 & \\
\hline $3-5$ & $17 / 57$ (30) & $2.4(0.9-6.3)$ & & $1.9(0.7-5.6)$ & \\
\hline$\leqslant 2$ & $6 / 48$ (13) & $0.9(0.3-2.8)$ & & $0.5(0.1-2.0)$ & \\
\hline \multicolumn{6}{|c|}{ Current smoker } \\
\hline Total & $31 / 159$ & & \multirow{3}{*}{$0.03^{\S}$} & & \\
\hline No & $24 / 101(24)$ & 1 & & NA & \\
\hline Yes & $7 / 58(12)$ & $0.4(0.4-1.3)$ & & NA & \\
\hline Influenza vacci & & & & & \\
\hline Total & $31 / 157$ & & & & \\
\hline Yes & $25 / 120(21)$ & 1 & 0.49 & NA & \\
\hline No & $6 / 37(16)$ & $0.7(0.3-1.9)$ & & NA & \\
\hline
\end{tabular}

Data are presented as $\mathrm{n} / \mathrm{N}(\%)$ or adjusted OR $(95 \% \mathrm{Cl})$, unless otherwise stated. Bold indicates statistical significance. NA: not included. \#: adjusted for age; ": adjusted for C-reactive protein and temperature on admission, age, and antibiotic use prior to admission; ${ }^{+}$: also associated with mixed viral or bacterial detection rate as a linear trend $(p<0.001)$; ${ }^{\S}$ : despite a $p$-value of $<0.1$ on univariate analysis, this variable could not be added to the multivariate models due to the small number of outcomes (i.e. detection of mixed viruses/bacteria, $n=31$ ).

detection, CRP and temperature. Unlike some previous studies, markers of severity including duration of hospital stay were not higher in patients with mixed infection compared to other groups [11].

Although previous studies have demonstrated more severe respiratory symptoms, prolonged recovery times and higher levels of serum interleukin- 6 levels in patients with virus-induced exacerbation compared to non-virus-induced exacerbations $[9,26]$, our study is the first to show that CRP levels are strongly associated with viral rather than bacterial detection. Several other studies have examined CRP levels in 

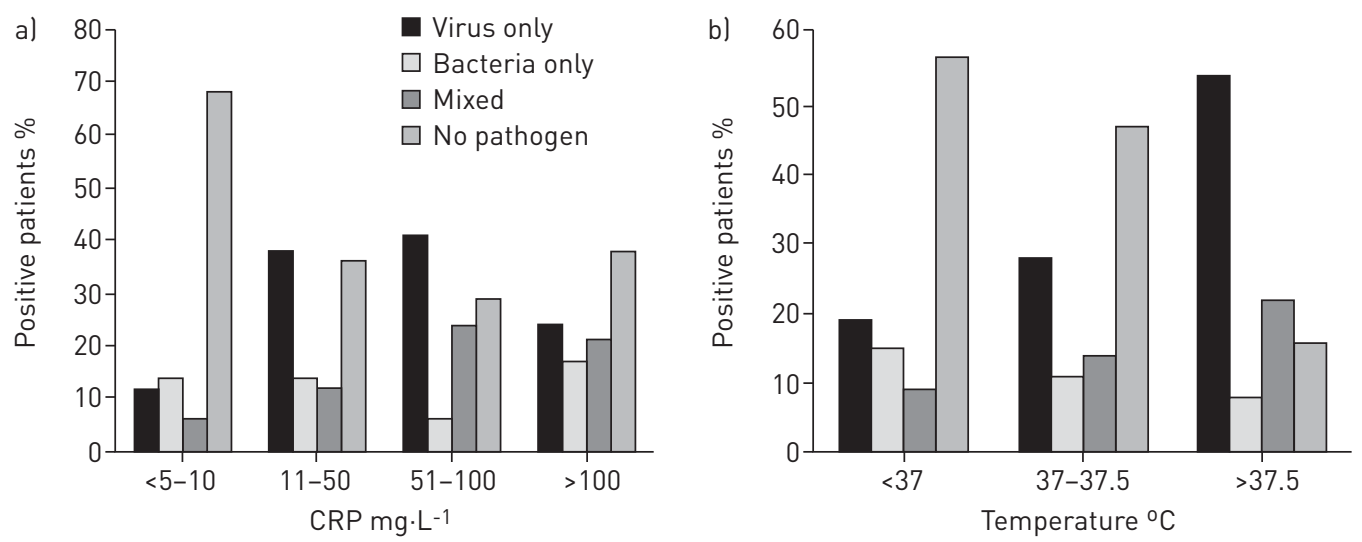

FIGURE 3 The proportion of patients with viruses only detected, bacteria only detected, mixed viral and bacterial detection, and no pathogens detected by a) serum C-reactive protein (CRP) and b) temperature.

viral and bacterial exacerbation and have generally not shown a difference in CRP levels between the two; however, these studies have been limited by smaller numbers of patients or have compared viral versus non-viral exacerbations so that many patients with viral detection have also had bacteria detected [11, 27, 28]. Furthermore, none of these studies have used multivariate analysis to examine the relationships between CRP levels and detection rate of viruses or bacteria in detail.

As bacterial detection occurs in patients across all levels of CRP and temperature, the implications of this study for antibiotic use in exacerbations of COPD are not clear. Antibiotics are frequently used in
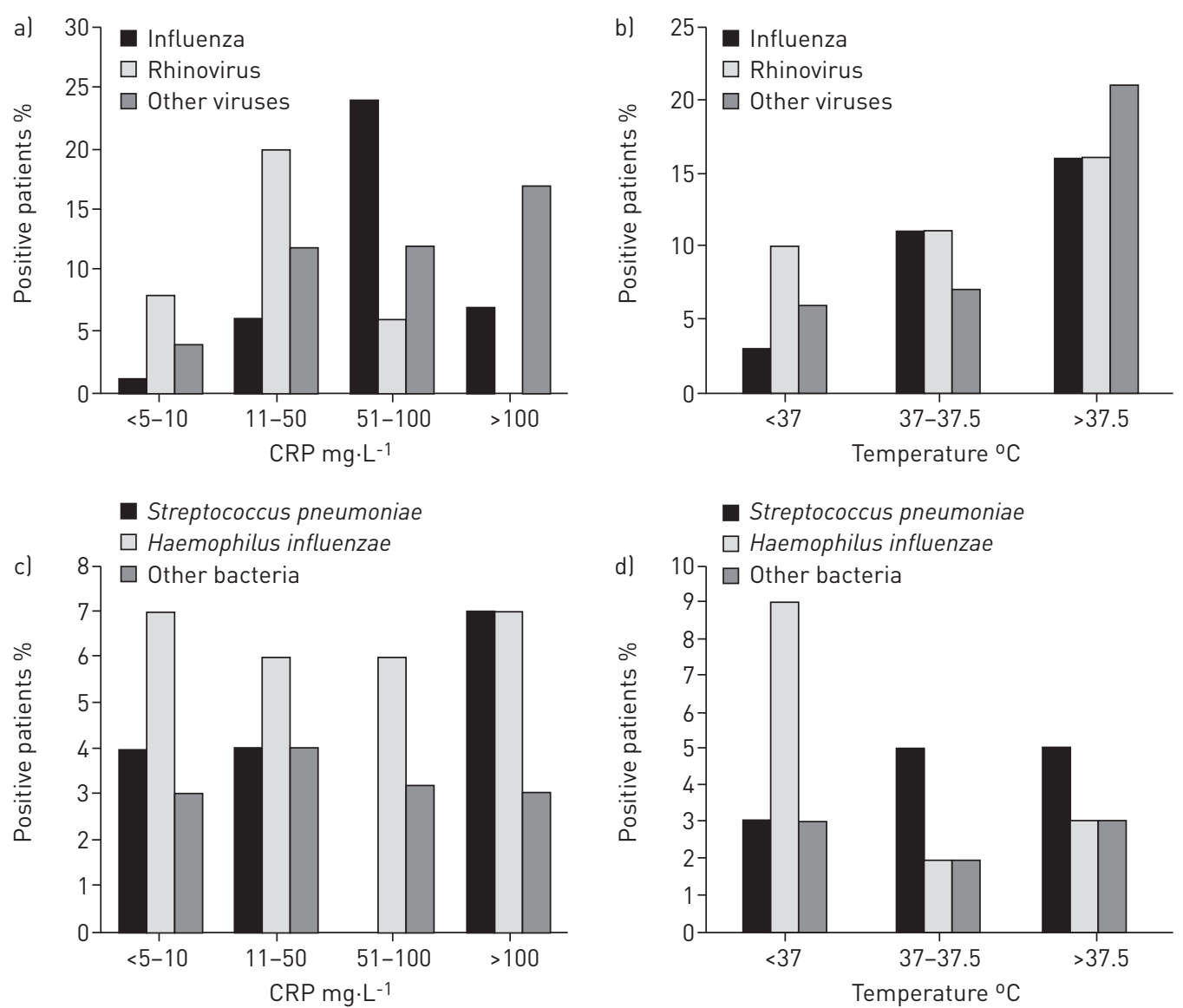

FIGURE 4 The proportion of patients positive for $a, b$ ) viral subtypes in patients with viruses only and $c$, d) bacterial subtypes in patients with bacteria only detected by a, c) serum C-reactive protein (CRP) and b, d) temperature. Other viruses include respiratory syncytial virus, parainfluenza, human metapneumovirus, coronavirus and adenovirus. Other bacteria include Moraxella catarrhalis, Pseudomonas aeruginosa and Staphylococcus aureus. 
exacerbations of COPD based on clinical criteria and have been shown to be beneficial in more severe cases [29]. Although viruses may be the main infectious agent initiating COPD exacerbations this does not preclude clinical benefit from antibiotics as the interaction between newly acquired viruses and chronically colonising bacteria may subsequently lead to an increase in bacterial load or a phenotypic change [14-16]. Furthermore, as the patients in this study had been unwell for $<7$ days it is possible that bacteria become more prevalent and important later in the course of a virally triggered exacerbation, as suggested by a recent study [16].

Whilst this is a "real world" clinical study it does have several limitations. As it is a study of hospitalised patients conducted outside of the summer months, findings cannot be generalised to patients treated for exacerbations in the community or during the summer months when the incidence of respiratory virus infection may be lower. As we excluded patients with exacerbations of COPD and radiological pneumonia it must be stressed that these findings apply only to patients with non-pneumonic exacerbations of COPD and cannot be extrapolated to patients with pneumonia or in those in whom pneumonia has not yet been excluded. As we excluded patients who had been unwell for $<7$ days the results of this study cannot be applied to those patients who have been unwell for longer periods. As it is an observational study and the numbers of patients with individual virus and bacterial types were low in some cases, we would suggest that the findings in this study are validated in a larger study.

Sputum bacterial cultures may underestimate the frequency of bacterial detection compared to newer molecular methods [30]. In our study we did not use molecular methods to identify or quantify bacteria and so cannot exclude the possibility that true bacterial detection rate was higher or that there was a relationship between CRP levels and quantitative bacterial load. Another possible weakness is that almost one-third of patients were already on antibiotics at enrolment which could have led to a reduction in the ability to culture bacteria in sputum and underestimated the proportion of patients with bacterial detection. However, the prior use of antibiotics was not associated with reduced detection rates of bacteria compared to those who had not received antibiotics in our multivariate model, giving reassurance that this did not affect our results. The rate of bacterial detection in our study is low compared to other studies of COPD exacerbation examining bacteria in sputum by conventional culture [12, 14, 31], although similar to others [29]. Our subgroup analysis of only those patients who were able to produce a sputum sample demonstrated a higher rate of bacterial detection overall (44\%), suggesting that this was the explanation for the lower rates in the main analysis. The associations between viral detection, bacterial detection, mixed viral/bacterial detection, CRP and temperature were not significantly different in this subgroup suggesting that the low detection rate in the main analysis has not altered these associations.

As CRP levels can be elevated in patients with COPD independently of exacerbation [32-34], this is a potential confounding factor in our study. Although studies have shown that baseline CRP levels can are elevated in patients with severe COPD this is using a highly sensitive CRP assay and corresponds to levels of $\sim 4-7 \mathrm{mg} \cdot \mathrm{L}^{-1}$ in more severe COPD compared to lower levels in less severe COPD or healthy controls [34]. In this study levels of CRP $<10 \mathrm{mg} \cdot \mathrm{L}^{-1}$ were not associated with an increase in viral detection rate and, in fact, levels of $<10 \mathrm{mg} \cdot \mathrm{L}^{-1}$ were independently associated with a lack of viral detection compared to higher levels. Therefore, small elevations in CRP below this level will not have influenced our results.

In conclusion, this work demonstrates that the detection rate of respiratory viruses in patients hospitalised with exacerbations of COPD is strongly associated with host inflammatory response as measured by CRP level and body temperature. This relationship reinforces evidence suggesting that respiratory viruses initiate a large proportion of exacerbations of COPD, and could be used in clinical practice to guide viral testing and directed antiviral therapy where available.

\section{Acknowledgements}

We would like to thank all the hospital staff at the University Hospitals of Leicester (Leicester, UK) involved in the care of the patients in this study and the laboratory staff involved in the processing of their samples. The assays used were developed as part of an ongoing collaboration between Health Protection Agency East of England and the Respiratory Virus Reference Laboratory at the Centre for Infections (London, UK). We thank Alison Bermingham (Respiratory Virus Unit, Public Health England, London) for her assistance in the validation of some of the PCR assays used in this study and Lily Telisinghe (Field Epidemiology Services, Public Health England and School of Social and Community Medicine, University of Bristol, Bristol, UK) for her assistance with the statistical analysis.

\section{References}

1 Stang P, Lydick E, Silberman C, et al. The prevalence of COPD: using smoking rates to estimate disease frequency in the general population. Chest 2000; 117: Suppl. 2, 354S-359S.

2 Niewoehner DE. The impact of severe exacerbations on quality of life and the clinical course of chronic obstructive pulmonary disease. Am J Med 2006; 119: 38-45.

3 Hirschmann JV. Do bacteria cause exacerbations of COPD? Chest 2000; 118: 193-203. 
Sethi S, Sethi R, Eschberger K, et al. Airway bacterial concentrations and exacerbations of chronic obstructive pulmonary disease. Am J Respir Crit Care Med 2007; 176: 356-361.

5 Sethi S, Wrona C, Grant BJ, et al. Strain specific immune response to Haemophilus influenzae in chronic obstructive pulmonary disease. Am J Respir Crit Care Med 2004; 169: 448-453.

6 Sethi S, Wrona C, Eschberger K, et al. Inflammatory profile of new bacterial strain exacerbations of chronic obstructive pulmonary disease. Am J Respir Crit Care Med 2008; 177: 491-497.

7 Murphy TF, Brauer AL, Grant BJ, et al. Moraxella catarrhalis in chronic obstructive pulmonary disease: burden of disease and immune response. Am J Respir Crit Care Med 2005; 172: 195-199.

8 Sethi S, Murphy TF. Infection in the pathogenesis and course of chronic obstructive pulmonary disease. $N$ Engl $J$ Med 2008; 359: 2355-2365.

9 Seemungal T, Harper-Owen R, Bhowmik A, et al. Respiratory viruses, symptoms, and inflammatory markers in acute exacerbations and stable chronic obstructive pulmonary disease. Am J Respir Crit Care Med 2001; 164: $1618-1623$.

10 Rohde G, Wiethege A, Borg I, et al. Respiratory viruses in exacerbations of chronic obstructive pulmonary disease requiring hospitalisation: a case-control study. Thorax 2003; 58: 37-42.

11 Kherad O, Kaiser L, Bridevaux PO, et al. Upper-respiratory viral infection, biomarkers, and COPD exacerbations. Chest 2010; 138: 896-904.

12 Papi A, Bellettato CM, Braccioni F, et al. Infections and airway inflammation in chronic obstructive pulmonary disease severe exacerbations. Am J Respir Crit Care Med 2006; 173: 1114-1121.

13 Gunawardana N, Finney L, Johnston SL, et al. Experimental rhinovirus infection in COPD: implications for antiviral therapies. Antiviral Res 2014; 102: 95-105.

14 Wilkinson TM, Hurst JR, Perera W, et al. Effect of interaction of bacterial and rhinoviral infection during chronic obstructive pulmonary disease exacerbations. Chest 2006; 129: 317-324.

15 Molyneaux PL, Mallia P, Cox MJ, et al. Outgrowth of the bacterial airway microbiome after rhinovirus exacerbation of chronic obstructive pulmonary disease. Am J Respir Crit Care Med 2013; 188: $1224-1231$.

16 George SN, Garcha DS, Mackay AJ, et al. Human rhinovirus infection during naturally occurring COPD exacerbations. Eur Respir J 2014; 44: 87-96.

17 Hurst JR, Donaldson GC, Perera WR, et al. Use of plasma biomarkers at exacerbation of chronic obstructive pulmonary disease. Am J Respir Crit Care Med 2006; 174: 867-874.

18 Stolz D, Christ-Crain M, Morgenthaler NG, et al. Copeptin, C-reactive protein, and procalcitonin as prognostic biomarkers in acute exacerbation of COPD. Chest 2007; 131: 1058-1067.

19 Brämer GR. International statistical classification of diseases and related health problems. Tenth revision. World Health Stat Q 1988; 41: 32-36.

20 Hutchinson EC, Curran MD, Read EK, et al. Mutational analysis of cis-acting RNA signals in segment 7 of influenza A virus. J Virol 2008; 82: 11869-11879.

21 Ellis JS, Curran MD. Simultaneous molecular detection and confirmation of influenza A H5, with internal control. In: Stephenson JR, Warnes A, eds. Diagnostic Virology Protocols (Methods in Molecular Biology series). 2nd Edn. Totowa, NJ, Humana Press 2011; pp. 161-181.

22 Heim A, Ebnet C, Harste G, et al. Rapid and quantitative detection of human adenovirus DNA by real-time PCR. J Med Virol 2003; 70: 228-239.

23 Dare R, Sanghavi S, Bullotta A, et al. Diagnosis of human metapneumovirus infection in immunosuppressed lung transplant recipients and children evaluated for pertussis. J Clin Microbiol 2007; 45: 548-552.

24 Melbye H, Hvidsten D, Holm A, et al. The course of C-reactive protein response in untreated upper respiratory tract infection. Br J Gen Pract 2004; 54: 653-658.

25 Murphy TF, Brauer AL, Schiffmacher AT, et al. Persistent colonization by Haemophilus influenzae in chronic obstructive pulmonary disease. Am J Respir Crit Care Med 2004; 170: 266.

26 Welte T, Miravitlles M. Viral, bacterial or both? Regardless, we need to treat infection in COPD. Eur Respir J 2014; 44: $11-13$.

27 Bafadhel M, McKenna S, Terry S, et al. Acute exacerbations of chronic obstructive pulmonary disease: identification of biologic clusters and their biomarkers. Am J Respir Crit Care Med 2011; 184: 662-671.

28 Bozinovski S, Hutchinson A, Thompson M, et al. Serum amyloid A is a biomarker of acute exacerbations of chronic obstructive pulmonary disease. Am J Respir Crit Care Med 2008; 177: 269-278.

29 Vollenweider DJ, Jarrett H, Steurer-Stey CA, et al. Antibiotics for exacerbations of chronic obstructive pulmonary disease. Cochrane Database Syst Rev 2012; 12: CD010257.

30 Garcha DS, Thurston SJ, Patel AR, et al. Changes in prevalence and load of airway bacteria using quantitative PCR in stable and exacerbated COPD. Thorax 2012; 67: 1075-1080.

31 Sethi S, Murphy TF. Bacterial infection in chronic obstructive pulmonary disease in 2000: a state-of-the-art review. Clin Microbiol Rev 2001; 14: 336-363.

32 Dahl M, Vestbo J, Lange P, et al. C-reactive protein as a predictor of prognosis in chronic obstructive pulmonary disease. Am J Respir Crit Care Med 2007; 175: 250-255.

33 Man SF, Connett JE, Anthonisen NR, et al. C reactive protein and mortality in mild to moderate chronic obstructive pulmonary disease. Thorax 2006; 61: 849-853.

34 de Torres JP, Cordoba-Lanus E, López-Aguilar C, et al. C-reactive protein levels and clinically important predictive outcomes in stable COPD patients. Eur Respir J 2006; 27: 902-907. 